\title{
Wiskundige modellering van die prestasiekoëffisiënt van 'n direkte-uitbreiding grootmaatmelkverkoeler op 'n plaas: 'n Veelvoudige lineêre regressie-benadering
}

\section{Outeurs: \\ Russel Mhundwa \\ Michael Simon \\ Affiliasies: \\ Fort Hare Instituut van \\ Tegnology, Universiteit van \\ Fort Hare, Suid-Africa \\ Korresponderende outeur: Russel Mhundwa \\ E-pos: \\ rmhundwa@gmail.com \\ Datums: \\ Ontvang: $\quad 10 / 02 / 21$ \\ Aanvaar: $\quad 27 / 07 / 21$ \\ Gepubliseer: 21/09/21}

Hoe om hierdie artikel aan te haal:

Russel Mhundwa, Michael

Simon, Wiskundige

modellering van die

prestasiekoëffisiënt van

'n direkte-uitbreiding grootmaatmelkverkoeler

op 'n plaas: 'n Veelvoudige

lineêre regressie-

benadering, Suid-

Afrikaanse Tydskrif vir

Natuurwetenskap en

Tegnologie 40(1) (2021).

https://doi.org/10.36303/

SATNT.2021.40.1.840

An English copy of this paper is available online at http://www.satnt.ac.za/

index.php/satnt/article/

view/840

\section{Kopiereg:}

(C) 2021. Authors.

Licensee: Die Suid-

Afrikaanse Akademie vir

Wetenskap en Kuns.

Hierdie werk is onder

die Creative Commons

Attribution License

gelisensieer.
In hierdie studie word 'n metode vir die voorspelling van die prestasiekoëffisiënt (COP) van 'n direkte uitbreiding grootmaatmelkverkoeler (DXBMC) aangebied in die vorm van ' $n$ meervoudige lineêre regressie (MLR) model. Die eksperimentele data wat gebruik is om die model te bou en te ontwikkel, is versamel vanaf ' $n$ DXBMC van $21 \mathrm{~m}^{3}$ met behulp van 'n dataverwerwingstelsel wat temperatuursensors, 'n omgewingstemperatuur- en relatiewe humiditeitsensor en 'n kragmeter bevat. Die studie het aan die lig gebring dat die COP van 'n DXBMC op die plaas met hoë akkuraatheid voorspel kan word. Daar is gevind dat die $\mathrm{R}^{2}$-waardes vir die voorspelling van die COP 0.957 is. Verder is die ontwikkelde model statisties beduidend, met ' $n$ p-waarde van $1,31 \times 10^{-120}$. Die model kan die COP met 'n relatiewe hoë akkuraatheid voorspel, soos aangedui deur 'n lae wortel gemiddelde kwadraatfout (RMSE) wat 0,0406 is met ' $n$ standaardfout van 0,0392 vir die gebruik van die model om die COP te voorspel, wat aandui die eksperimentele data lewer' $n$ goeie pasvorm. Die ReliefF-algoritme en 2D-simulasiegrafieke het aangedui dat energieverbruik en volume melk primêr bydra tot die COP. Daarenteen was melktemperatuur, omgewingstemperatuur en relatiewe humiditeit sekondêre bygedraende faktore. Die studie het bevind dat elektriese energie die belangrikste faktor is wat die COP van die DXBMC op 'n plaas beïnvloed. Dus kan energie-doeltreffendheidsinisiatiewe in melkboerderye help om die energieverbruik te optimaliseer.

Sleutelwoorde: Direkte uitsetting, grootmaatmelkverkoeler, regressie, prestasiekoëffisiënt; verkoeling van melk; modellering

Mathematical modelling of the coefficient of performance of an on-farm direct expansion bulk milk cooler: A multiple linear regression approach: In this study, a method for predicting the coefficient of performance (COP) of an on farm-direct expansion bulk milk cooler (DXBMC) is presented in the form of a multiple linear regression (MLR) model. The experimental data used to build and develop the model was collected from a $21 \mathrm{~m}^{3} \mathrm{DXBMC}$ utilising a data acquisition system comprising temperature sensors, an ambient temperature and relative humidity sensor, and a power meter. The study revealed that the COP of an onfarm DXBMC could be predicted using an MLR model with high accuracy. The R2 value for predicting the COP was found to be 0.957 . Furthermore, the developed model is statistically significant as was deduced by significance $p=1.31 \times 10^{-120}$. The model can predict the COP with relatively high precision as indicated by a low root mean squared error (RMSE) = 0.0406 with a standard error for using the model to predict the COP of 0.0392 implying the experimental data produces a good fit. The ReliefF algorithm and 2D simulation plots indicated that energy consumption and volume of milk were primary contributors to the COP. In contrast, milk temperature, ambient temperature and relative humidity were secondary contributors. The study found that electrical energy is the most critical factor influencing the COP of the on-farm DXBMC. Thus, energy efficiency initiatives in dairy farms would help to optimise energy consumption.

Keywords: direct expansion bulk milk cooler, regression, coefficient of performance, dairy milk cooling, modelling 


\section{Inleiding}

Die aantal melkprodusente in Suid-Afrika het tussen Januarie 2011 en Januarie 2020 met 57\% afgeneem. Maar tussen 2011-2019 het melkproduksie en melkproduksie per produsent met $26 \%$ en $291 \%$ gestyg. In 2019 het die WesKaap Provinsie, Oos-Kaap en KwaZulu Natal ongeveer $87,5 \%$ van die totale melkproduksie in die land gelewer. Die aantal koeie wat gemelk word, wissel baie tussen produsente, en die Oos-Kaap het die hoogste gemiddeld van 814 koeie per produsent (International Farm Comparison Network, 2019). Dit is interessant dat $98 \%$ van die rou melk in Suid-Afrika gelewer moet word vir verdere verwerking, en dus is die hantering van melk by die melkplaas van kardinale belang om besoedeling te voorkom. In 'n tipiese verwerkingsaanleg moet melk 'n reeks verwerkingsaktiwiteite ondergaan voordat dit veilig vir menslike gebruik gelewer word. Dit behels die hantering van rou melk, verheldering, homogenisering, pasteurisasie en verkoeling (Modi en Prajapat, 2014). Dit dui daarop dat die melkgehalte op die melkplaas van melk tot opberging van die allergrootste belang is. Melkboerdery is ' $n$ energieintensiewe onderneming en behels verskillende prosesse: ventilasie, beligting, waterverhitting, melkverkoeling, vervoer en besproeiing waar ' $n$ aansienlike hoeveelheid energie benodig word. Tydens hierdie prosesse benodig melkverkoeling ongeveer $20-36 \%$ van die totale energieverbruik (Peterson, 2008; Upton et al., 2013). Die doeltreffende werking van die verkoelingstelsel is dus van kardinale belang vir enige melkboerdery, aangesien dit aanvaarbare kwaliteit van die produk verseker.

Daar word spesifiek veronderstel dat melk vinnig van 35 ${ }^{\circ} \mathrm{C}-37^{\circ} \mathrm{C}$ tot 'n opbergtemperatuur van $4{ }^{\circ} \mathrm{C}$ afgekoel moet word om mikrobiese aktiwiteit te beperk (Lewis en Heppell, 2000; Holm et al., 2004; Upton et al., 2010) . Die verkoeling kan direk of deur vooraf verkoeling gedoen word (Saravacos en Kostaropoulos, 2002, Mhundwa, 2017). Vervolgens word die melk in die DXBMC geberg en in die meeste melkboerderye neem die opslag gewoonlik hoogstens twee dae voordat dit deur verkoelde tenkwaens versamel kan word, wat die melk op $4{ }^{\circ} \mathrm{C}$ hou. Die werkverrigting van 'n verkoelingstelsel word bepaal deur die prestasiekoëffisiënt (COP), dit dui op die hitte wat uit die melk verwyder word per eenheid energie wat die BMC gebruik om die hitte te verwyder. Die COP hang baie af van die buitetemperatuur en die benodigde melktemperatuur. Op 'n melkplaas is hoër COP's aanduidend van doeltreffendheid, laer elektriese energieverbruik en dus laer bedryfskoste vir die boer. Die COP van 'n DXBMC kan wissel van 2,6 tot 5 (Mhundwa et al., 2017). Soos enige ander stelsel wat op die dampkompressie-verkoelsiklus (VCRC) werk, word dit beheer deur die ontwerp, die bedryfsomstandighede en ligging daarvan. Om 'n optimale COP vir die DXBMC te bewerkstellig, is professionele installasie van die stelsel egter noodsaaklik sowel as die daaglikse werking van die DXBMC. Die COP van die DXBMC kan verbeter word deur die verkoeling van afvalhitte uit die kondenseerder en die gebruik van waterverkoelde kondenseerders in plaas van lugverkoelde kondenseerders (Sapali et al., 2014). Verskeie studies oor die COP van verkoelingstoerusting kan in die literatuur gevind word, wat wissel van huishoudelike-, industriële- en vervoertoerusting. Tian et al. (2019) het 'n metode ontwikkel om die COP van 'n skroefverkoeler op die perseel te voorspel. Hulle studie het kunsmatige neurale netwerke (ANN) as modelleringstegniek gebruik. Opalic (2020) hetook'n ANN-modellering van $\mathrm{CO}_{2}$-verkoelmiddelverkoelingstelsel COP vir 'n pakhuis ontwikkel. Zhu et al. (2019) Zhu et al. (2013) stel 'n generiese simulasiemodel voor vir prestasie- en kontrole analise. Laidi en Hanini (2013) het 'n optimale voorspelling van die COP-sonkrag ontwikkel deur middel van ANN-modellering deur adsorpsie-verkoelingstelsel deur sonkrag; Artuso et al. (2020) het 'n nuwe verkoelingseenheid vir koelvervoer gemodelleer. Nikbakhti et al. (2020) het 'n termodinamiese model met enkelparameters ontwikkel vir prestasie-analise van 'n geïntegreerde verkoelingstelsel vir adsorpsie en absorpsie. Lee en $\mathrm{Lu}$ (2010) het die werkverrigting van waterkoelers met dampkompressie geëvalueer. Hulle studie het gefokus op die gebruik van empiries-gebaseerde modelle wat bereik is met behulp van die metode van die minste vierkante. Die ontwikkelde modelle het die energieprestasie van die waterkoelers voorspel. Dit is die moeite werd om te noem dat die COP-prestasie van ' $n$ regstreekse uitbreiding grootmaatmelkverkoeler nie voldoende in die literatuur gerapporteer word nie. Hierdie studie poog om die COP-prestasie van 'n DXBMC te voorspel deur middel van veelvuldige lineêre regressiemodelleringstegnieke. Hierdie studie het ten doel om 'n wiskundige model te ontwikkel wat die prestasie van 'n direkte uitbreiding op 'n plaas DXBMC in terme van sy COP vaslê. Die ontwikkelde model vir die DXBMC op die plaas help om die impak van die melkbelading en omgewingstoestande op die COP te visualiseer. Deur die ReliefFalgoritme is die invloed en bydrae van elke voorspellingsveranderlike tot die COP afgelei. Verder is die effekte van elke voorspeller op die COP afgelei deur middel van die 2D-simulasiegrafieke wat variërende enkelvoorspellers toelaat terwyl die ander konstant gehou word.

\section{Materiale en metodes}

\section{Stelselbeskrywing}

Die studie het plaasgevind op ' $n$ bestaande melkplaas in die Oos-Kaap Provinsie van Suid-Afrika met 'n DXBMC van $21 \mathrm{~m}^{3}$ en gemiddeld 500 melkkoeie. Die melk is twee keer per dag (AM- en PM-melk) gedoen. Gedurende die moniteringstydperk is die melk elke dag en elke twee dae versamel. Prestasiemonitering was van April 2016 tot Maart 2017.

Die DXBMC het ' $n$ totaal van vier afsonderlike kondenseereenhede gehad, en almal het dieselfde verdamper gebruik. Die verdamper vorm die onderkant van die binneste tenk van die DXBMC, en 'n isolasie-laag het die 
binneste tenk en die buitenste tenk geskei. Tabel 1 hieronder som die spesifikasies van die stelsel op die plaas op.

TABEL 1: Stelselbeskrywing en spesifikasies.

\begin{tabular}{l|c|c}
\hline Beskrywing & Spesifikasies Hoeveelheid & Hoeveelheid \\
\hline DXBMC & $21 \mathrm{~m}^{3}$, silindries, direkte uitbreiding, & 1 \\
melkmasjien & met horisontale roerders & \\
Kondenserende eenhede & Copeland Scroll kompressors & 1 \\
\hline
\end{tabular}

Tabel 2 toon die sensors, meter en logger wat gebruik is vir die dataverkrygingstelsel (DAS - dataverkrygingstelsel, data-insamelstelsel.) wat op die melkplaas ontwerp, gebou en geïnstalleer is.

TABEL 2: Lys van toerusting wat vir die DAS gebruik word.

\begin{tabular}{l|c}
\hline Toerusting Beskrywing & Hoeveelheid \\
\hline Landis en Gyr E650 kragmeter & 1 \\
HOBO ProV2 relatiewe humiditeit en omgewingstemperatuursensor & 1 \\
HOBO TMC6-HE temperatuursensors & 2 \\
UX120-006M 4-kanaal analoog datalogger & 2 \\
\hline
\end{tabular}

Die HOBO TMC6-HE temperatuursensor is geïnstalleer op die melkafvoerpyp en in die kamer van die DXBMC. Die sensors is gekoppel aan die UX120-006M 4-kanaal analoog datalogger wat ingestel is om met tussenposes van vyf minute te noteer. Die Landis en Gyr E650 meter met 'n ingeboude logfunksie het die kragverbruik (aktiewe krag, skynbare krag en reaktiewe krag) van die DXBMC met dieselfde tussenposes van vyf minute tydens die afkoeling van melk van die aanvanklike temperatuur tot die finale vereiste temperatuur $4^{\circ} \mathrm{C}$ (afkoelsiklus) noteer. 'n Relatiewe humiditeit en omgewingstemperatuur HOBO Pro V2 -sensor met ' $n$ inherente aantekenvermoë het die plaas se omgewingstemperatuur en relatiewe humiditeit noteer. Die hoeveelheid melk wat geproduseer is, is verkry uit die boerderyrekords. Volgens die roumelkstandaarde word die finale temperatuur van die melk aangeteken by 'n bergingstemperatuur van $4^{\circ} \mathrm{C}$. Die skematiese uitleg van die eksperiment en hoe die DAS verbind is, word in figuur 1 getoon.

\section{Berekeninge en teorie}

Die berekende elektriese energieverbruik $\left(\mathrm{E}_{\text {cal }}\right)$ vir die hele duur van die koelsiklus word gegee deur vergelyking 5.1:

$$
E_{c a l}=P x t
$$

Waar:

$\mathrm{P}=$ kragverbruik van die DXBMC $(\mathrm{kW})$

$\mathrm{t}=$ tyd wat die DXBMC neem om 'n afkoelsiklus te voltooi (ure)

Die totale termiese energie wat tydens die afkoeling uit die melk verwyder is, word deur vergelyking 2 gegee

$$
Q_{m}=\frac{m C p_{m}\left(T_{m i}-T_{m j}\right)}{3600}
$$

Waar:

$\mathrm{Q}_{\mathrm{m}}=$ termiese energie wat uit die melk verwyder word tydens afkoeling $(\mathrm{kWh})$

$\mathrm{m}$ = massa melk afgekoel tydens 'n afkoelsiklus $(\mathrm{kg})$

$\mathrm{C}_{\mathrm{pm}}=$ Spesifieke warmtekapasiteit van melk (3.93kJ/kg.K)

$\mathrm{T}_{\mathrm{mi}}=$ gemiddelde aanvangstemperatuur van melk $\left({ }^{\circ} \mathrm{C}\right)$

$\mathrm{T}_{\mathrm{mf}}=$ gemiddelde eindtemperatuur van melk $\left({ }^{\circ} \mathrm{C}\right)$

Die berekende COP $\left(\mathrm{COP}_{\text {cal }}\right)$ is die verhouding van die termiese energie wat tydens die verkoeling proses $\left(Q_{m}\right)$ uit die melk verwyder word tot die ingevoerde elektriese energie (E). Die berekende COP word gegee deur vergelyking 3

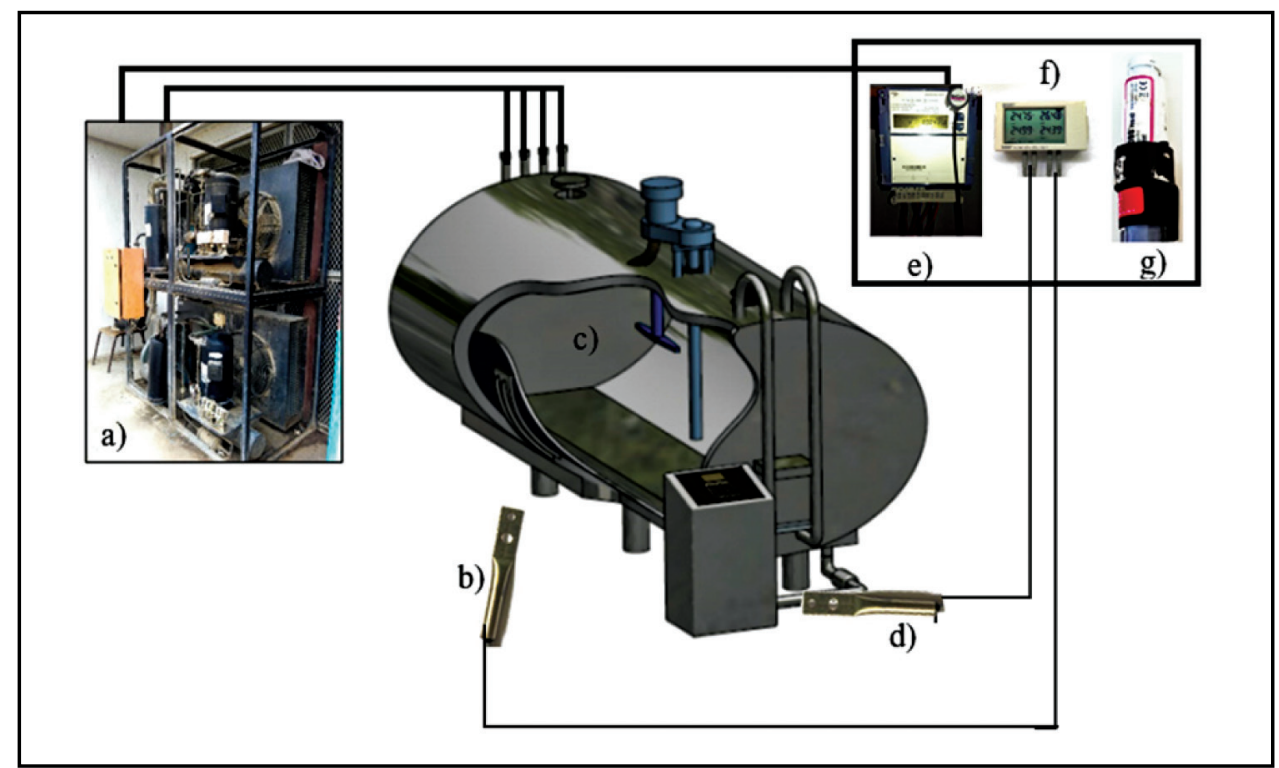

FIGUUR 1: Skematiese uitleg vir die eksperiment.

a) kondenseereenheid, b) kamertemperatuursensor, c) grootmelkkoeler, d) melktemperatuur-sensor, e) kragmeter, f) vierkanaal datalogger, g) relatiewe humiditeit en omgewingstemperatuur- logger 


$$
C O P_{c a l}=\frac{Q_{m}}{E}
$$

\section{Modelformulering}

Hierdie studie gebruik 'n eenvoudige enkeluitset en veelvuldige insette multi-lineêre regressiemodel (MLRM) met voorspellers: die volume melk, die temperatuur van melk, elektriese energie, kamertemperatuur, omgewingstemperatuur en relatiewe humiditeit. ' $n$ MLR -model is ' $n$ wiskundige vergelyking wat die gewenste uitset korreleer met insetparameters. Dit het 'n dwingende konstante en skaleringskonstante van elk van die invoerparameters en is bepaal deur die gewone kleinste-vierkantmetode. MLR -model is 'n eenvoudige vorm van 'n kunsmatige neurale netwerkmodel. Die voordeel van die MLR -model is dat dit die variasie van elke invoerparameter maklik kan voorspel met die gewenste uitset (Mhundwa en Simon, 2020). Veranderlike seleksie is gebaseer op 'n korrelasiematriks vir die voorspellers en die uitset. Vergelyking 4 dui die model aan.

$$
C O P_{\text {mod }}=\alpha+\beta E+\delta V_{m}+\varepsilon T_{a} R H+\lambda T_{m}
$$

Waar:

$\alpha=$ Dwingkonstante vir COP -model

$\beta=$ Skaalkonstante vir energieverbruik (kWh)

$\delta=$ Skaalkonstante vir die volume melk (Ltrs)

$\varepsilon=$ Skaalkonstante vir die produk van omgewingstemperatuur en relatiewe humiditeit $\left({ }^{\circ} \mathrm{C} \%\right)$

$\lambda=$ Skaalkonstante vir melktemperatuur $\left({ }^{\circ} \mathrm{C}\right)$

$\mathrm{T}_{\mathrm{m}}$ - Temperatuur van die rou melk $\left({ }^{\circ} \mathrm{C}\right)$

$\mathrm{T}_{\mathrm{a}}=$ Omgewingstemperatuur $\left({ }^{\circ} \mathrm{C}\right)$

R.H. = Relatiewe humiditeit $(\%)$

$\mathrm{V}_{\mathrm{m}}=$ Volume melk produseer (ltr.)

$\mathrm{E}=$ Energieverbruik $(\mathrm{kWh})$

\section{Voorspeller Belangrikheid}

Die voorspellers van die multi-lineêre regressiemodel is gerangskik volgens die belangrikheid van hul gewigsbydrae tot die opbrengs (Millilan en Johnson, 1982; Robnik-Šikonja en Kononenko 2003). Die rangorde van voorspellers is gedoen met behulp van die ReliefF -algoritme in die Matlab Statistical toolbox (Palm, 2010) om die grootte en belangrikheid van die voorspellers met betrekking tot die COP vir die DXBMC te onderskei. Die ReliefF -algoritme bepaal vir watter voorspellers die COP die sensitiefste is.

\section{Modeltoets en validering}

Die ontwikkelde modelgeskiktheid vir die eksperimentele data is geëvalueer met behulp van die bepalingskoëffisiënt $\left(\mathrm{R}^{2}\right)$. Die modelontwikkeling en validering het onderskeidelik $70 \%$ en $30 \%$ van die datastel gebruik. Die gemiddelde kwadraatvoorspellingsfout (MSPE), wortelgemiddelde vierkante fout (RMSE) en relatiewe voorspellingsfout (RPE) vorm die basis vir die evaluering van die presisie, akkuraatheid en vooroordeel van die modelle, soos beklemtoon deur Bibby en Toutenburg (1977) en Rook et al. (1990).

\section{Resultate en bespreking}

Data is vir twaalf maande ingesamel vir die twee afsonderlike melkperiodes (dit is die AM -melk- en die PM -melktydperke) en is gebruik om die stelsel se algehele daaglikse prestasie -evaluering uit te voer. Tabel 3 bied 'n opsomming van die data wat vir hierdie studie ingesamel is

Soos uit die tabel gesien kan word, het die DXBMC se energieverbruik gewissel tussen 68,50 kWh en 184,49 kWh. Die COP vir die DXBMC was gemiddeld 2,19. Dit is opmerklik dat lae melkvolumes lae COP's vir die DXBMC gehad het ondanks die lae kamertemperature wat aangeteken is. Oor die algemeen het die AM -melktydperke hoë melkvolume sowel as hoër COP -waardes. 'n Geringe variasie in die melktemperatuur is geïdentifiseer wat deur die kamertemperatuur beïnvloed is, aangesien die melkaanvoerpypleidings nie geïsoleer is nie; geen beduidende verskil is egter waargeneem. Dit is opmerklik dat daar 'n toename in die COP was met' $n$ toename in die melkvolume, wat dui op die verbeterde prestasie van die DXBMC by hoë melkvolumes. As dit saam ontleed word, was energie, die volume melk en melktemperatuur betekenisvol geassosieer met die COP van die DXBMC $(\mathrm{p}<0,001)$. Die ander veranderlikes, omgewingstemperatuur, relatiewe humiditeit en kamertemperatuur was nie beduidend geassosieer met die COP nie. Voortaan vorm die volume melk en energie deel van die finale model. Aangesien die prestasie van 'n verkoelingstelsel egter beïnvloed word deur die omgewingstoestande en as gevolg van die noue assosiasie van omgewingstemperatuur en kamertemperatuur (Mhundwa et al. 2018), is 'n produk van omgewingstemperatuur en relatiewe humuditeit( $\mathrm{RH})$ ook ingesluit in die model.Met behulp van die kriteria van 70:30 (modelontwikkeling en validering), is die MLR -model ontwikkel om die uitwerking van verskillende voorspellers op die COP van die DXBMC te bepaal. Tabel 4 bied die koëffisiënte van die skaalparameters aan. Die skaalwaardes

TABEL 3: Opsomming van die data wat vir hierdie studie ingesamel is.

\begin{tabular}{l|c|c|c|c|c|c|c|c}
\hline & $\mathrm{E}(\mathrm{kWh})$ & $\mathrm{V}_{\mathrm{m}}$ (Ltrs) & $\mathrm{T}_{\mathrm{a}}\left({ }^{\circ} \mathrm{C}\right)$ & R.H. (\%) & $\mathrm{T}_{\mathrm{m}}\left({ }^{\circ} \mathrm{C}\right)$ & $\mathrm{T}_{\mathrm{r}}\left({ }^{\circ} \mathrm{C}\right)$ & $\mathbf{C O P}$ \\
\hline Minimum & 68.50 & $5,034.10$ & 2.12 & 13.22 & 29.23 & 5.63 \\
Gemiddeld & 110.84 & $7,371.16$ & 17.58 & 68.35 & 33.19 & 1.78 \\
Maksimum & 184.49 & 10,199 & 35.27 & 100 & 40.33 & 2.19 \\
\hline
\end{tabular}


het voorspel dat die elektriese energieverbruik van die DXBMC sou toeneem as daar ' $n$ toename in $\mathrm{Vm}$ aan die DXBMC en Tm was.

As daar 'n toename in E, Ta en Tr was, sou die COP van die stelsel afneem. 'n Toename in R.H. en Ta het gelei tot 'n effense vermindering van die COP, alhoewel hierdie verskynsel nie gelyktydig kon voorkom nie. Dit is die moeite werd om te noem dat Ta en R.H. lae vlakke van betekenis toon in die voorspelling van die COP, soos beklemtoon deur die waardes groter as 0.05 (Tabel 4). Soos gesien in tabel 4 , verminder die COP van die DXBMC met 0,01796 vir elke $\mathrm{kWh}$ toename in energieverbruik. ' $\mathrm{n}$ Toename in melkvolume met 'n liter sou die COP van die DXBMC met 0.0003 toeneem. Oor die algemeen sou die omgewingstoestande rondom die DXBMC waarskynlik die COP verminder vir elke graad Celsius toename in omgewingstemperatuur en kamertemperatuur. Die waardes vir Energie, Vm en Tm is baie kleiner.

'n 2D -snygrafiek in figuur 3 bied die variasie van elke voorspeller aan terwyl die res konstant gehou word. Die grafiek lei die algehele effek van elke voorspeller visueel af tot die gewenste respons (COP). Die soliede middellyn van elke voorspellerafdeling dui op die verandering in die uitset gebaseer op die voorspellerveranderlike as alle ander voorspellers konstant bly. Die snygrafiek toon ook die 95\% onderste en boonste vertrouensgrense (stippelkurwes) vir die voorspelde COP aan. Ons kan uit hierdie grafiek aflei dat 'n toename in energieverbruik met 'n eenheid $\mathrm{kWh}$ waarskynlik tot 'n verminderde COP van $0,9 \%$ sal lei, terwyl' $n$ toename in die melkvolume met een liter die COP met $0,0134 \%$ sal verhoog. Dit is belangrik om dit op te let dat die toename van ander voorspellers nie veel verandering in die COP getoon het nie. Figuur 2 illustreer die berekende COP en gemodelleerde COP.

Soos getoon in Figuur 3 boots die gemodelleerde COP die berekende COP na met ' $n$ aangepaste $R^{2}=0,957$. Dit dui aan dat 95,7\% van die data se variasie deur die MLR -model verduidelik word deur die voorspellers te gebruik. Dit dui op 'n sterk verband tussen die voorspellers en die geteikende COP op 'n vertrouensvlak van 95\%. Die verskil tussen die gemiddele van $\mathrm{COP}_{\text {cal }}$ en $\mathrm{COP}_{\text {mod }}$ was statisties onbeduidend met ' $n$ p-waarde $=0,992$. Verder is die ontwikkelde model statisties betekenisvol, soos afgelei van die p-waarde van $1,31 \times 10^{-120}$. Die model kan die COP met relatief hoë presisie voorspel, soos aangedui deur 'n lae RMSE $=0.0406$ met 'n standaardfout van 0.0392 vir die gebruik van die model om die COP te voorspel, wat impliseer dat die eksperimentele data 'n goeie pasvorm lewer. Figuur 4 toon die oorblywende grafiek vir die gemodelleerde COP.

Die residuele grafiek toon geen duidelike patroon van die residue nie wat die willekeurigheid van die residue aandui, met die meeste van hulle naby aan die nulresidu. Figuur 5 illustreer die uitwerking van elke voorspeller op die COP van die DXBMC.

Gebaseer op Figuur 5, toon hierdie grafiek aan dat die energieverbruik deur die DXBMC 'n negatiewe uitwerking op die prestasie van die DXBMC het. 'n Toename in energieverbruik van $62,85 \%(68,503 \mathrm{kWh}$ tot $184,49 \mathrm{kWh})$ sal die COP van die DXBMC met 2,08 verminder. Aan die ander kant sal die toename van die melkvolume met 50,64\% (5 034 tot 10 199) die COP van die stelsel waarskynlik met 1,496 verhoog. 'n Verhoging van die melktemperatuur met

TABEL 4: Invoerparameters en skaalkoëffisiënte vir die COP van die DXBMC

\begin{tabular}{|c|c|c|c|c|c|}
\hline Voorspeller & Simbool & Skaal Notasie & Skaal Konstante & P-waarde & Uitset \\
\hline Energie & $\bar{E}$ & $\beta$ & -0.01796 & $2.71 \times 10^{-99}$ & \\
\hline Volume melk & $v_{m}$ & $\delta$ & 0.0003 & $1.16 \times 10^{-112}$ & \\
\hline Omgewingstemperatuur en relatiewe humiditeit & $\mathrm{T}_{\mathrm{a}} \mathrm{RH}$ & $\varepsilon$ & $-3.39 \times 10^{-6}$ & 0.714 & COP \\
\hline Melktemperatuur & $\mathrm{T}_{\mathrm{m}}$ & $\lambda$ & 0.064 & $8.82 \times 10^{-49}$ & \\
\hline Konstante & & $\alpha$ & -0.0165 & 0.867 & \\
\hline
\end{tabular}

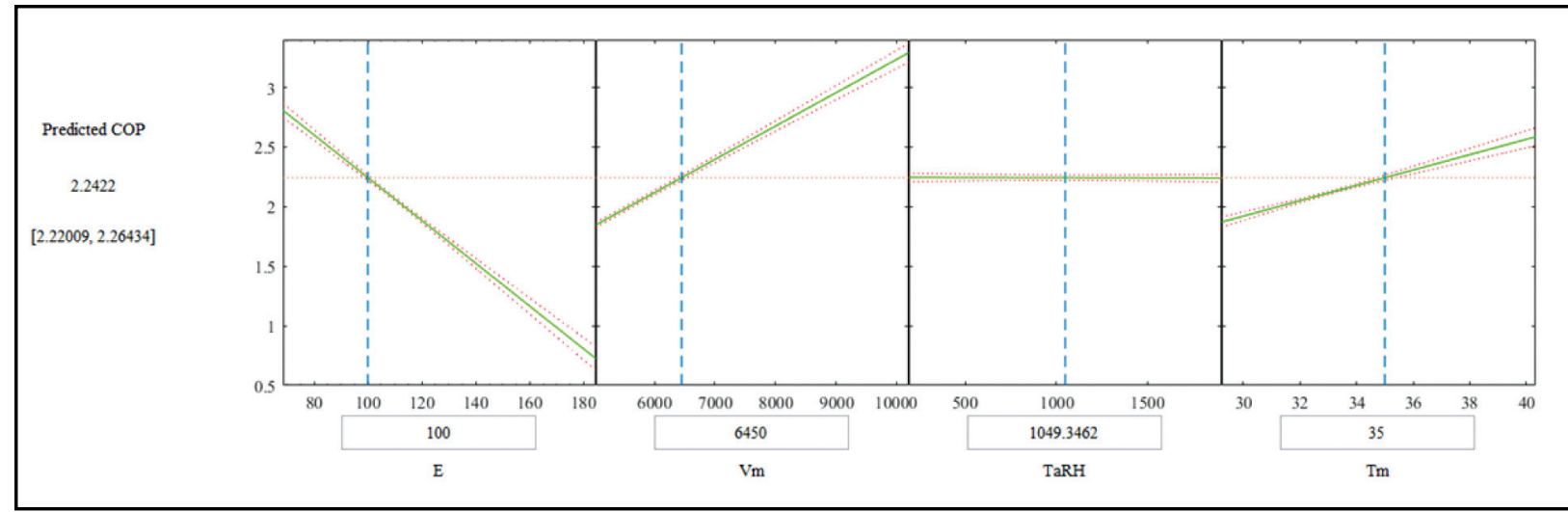

FIGUUR 2: 2D snygrafiek van voorspellers en COP vir die op 'n plaas DXBMC. 


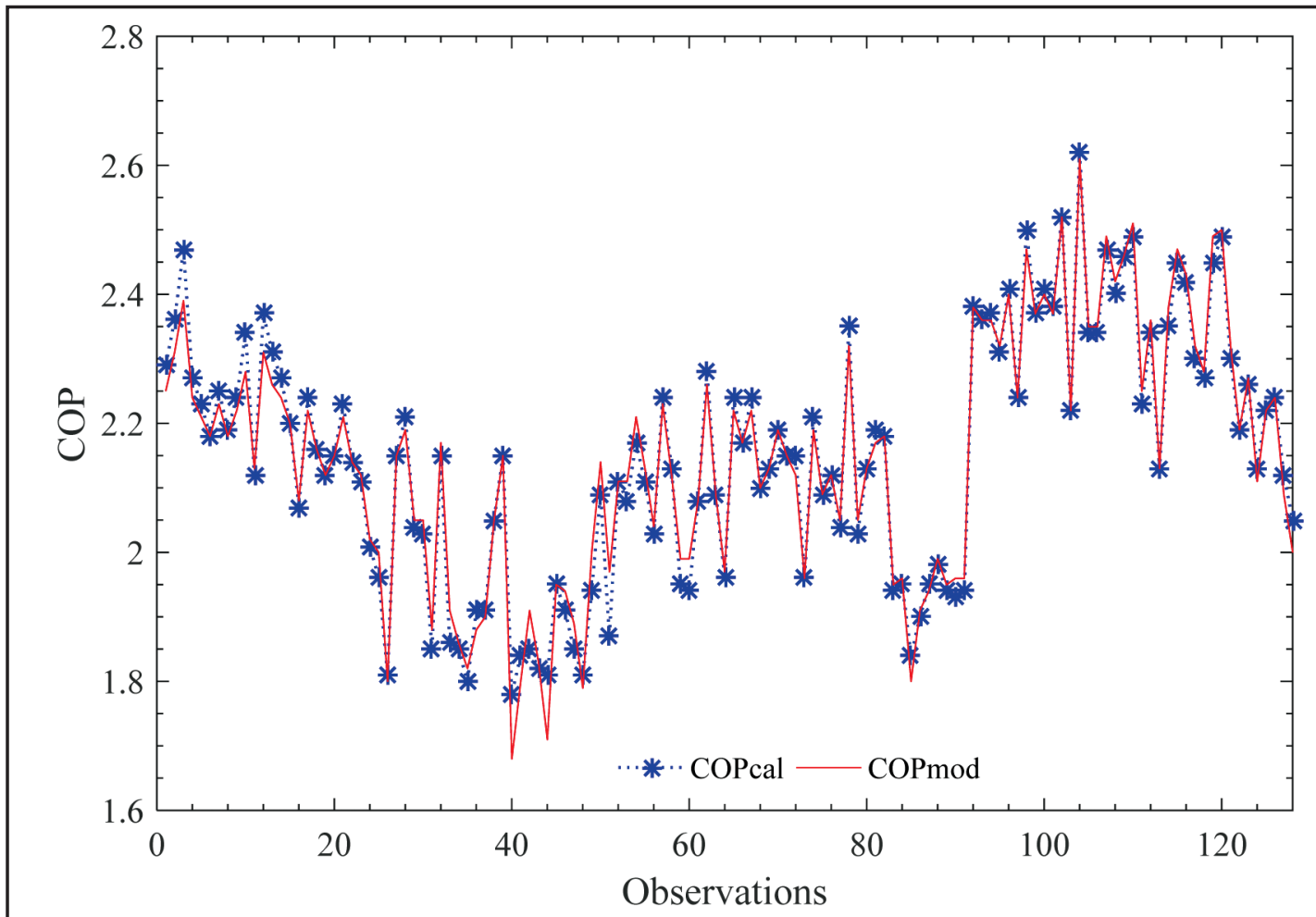

FIGUUR 3: Berekende COP en gemodelleerde COP vir 'n DXBMC op 'n plaas.

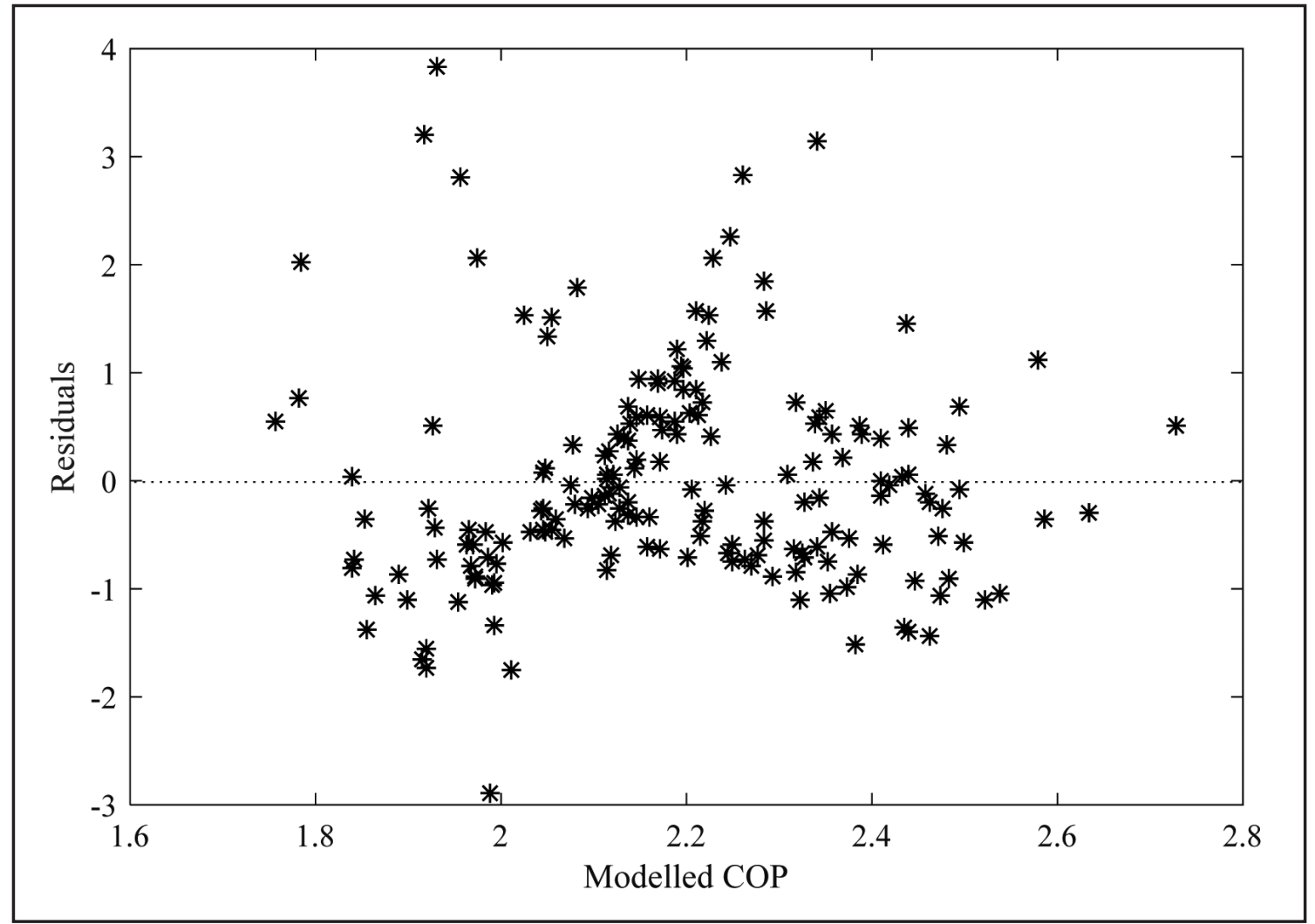

FIGUUR 4: Residuele en gemodelleerde COP vir die DXBMC op 'n plaas. 


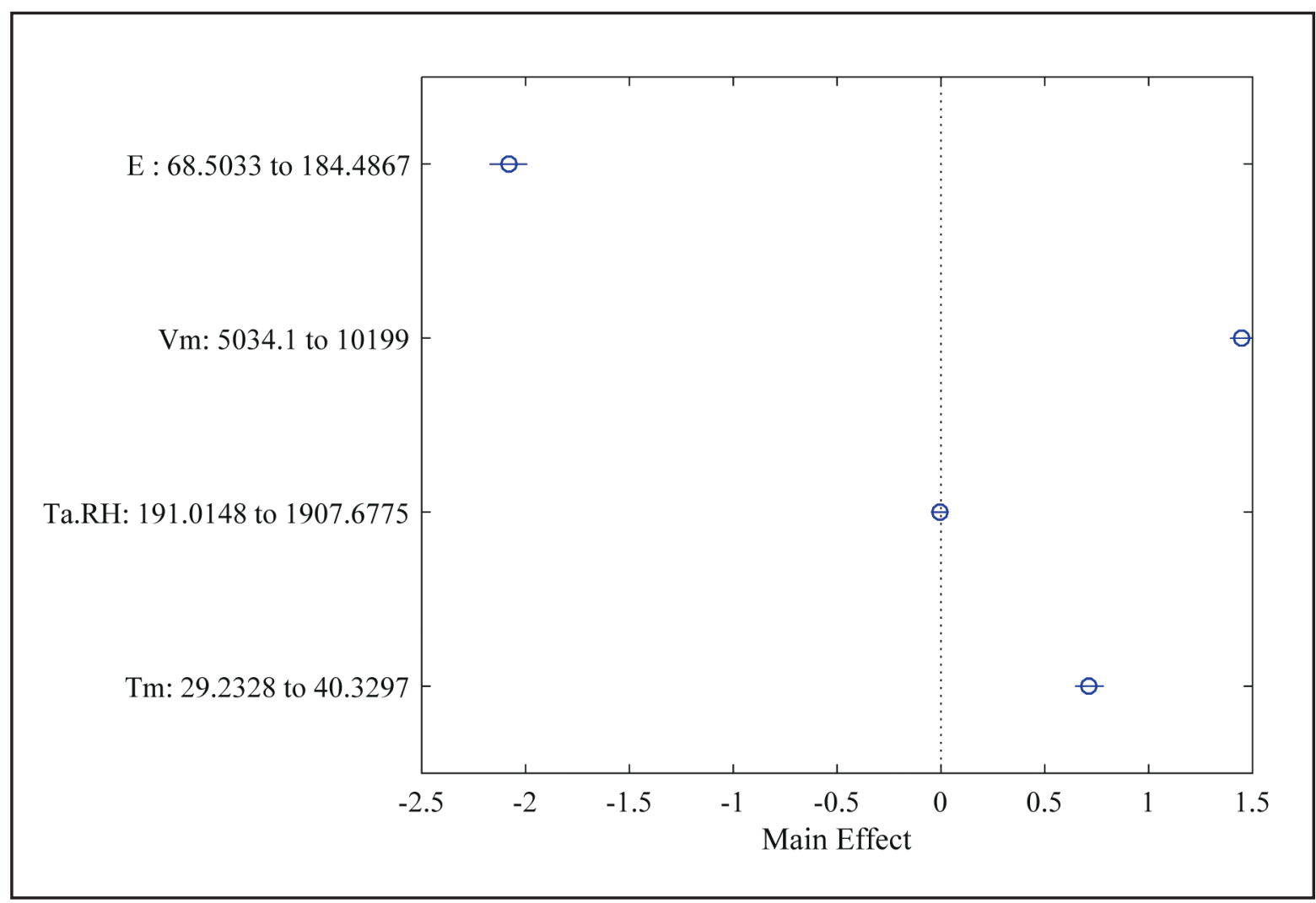

FIGUUR 5: Effekte van elke voorspeller op die COP van die DXBMC op die plaas.

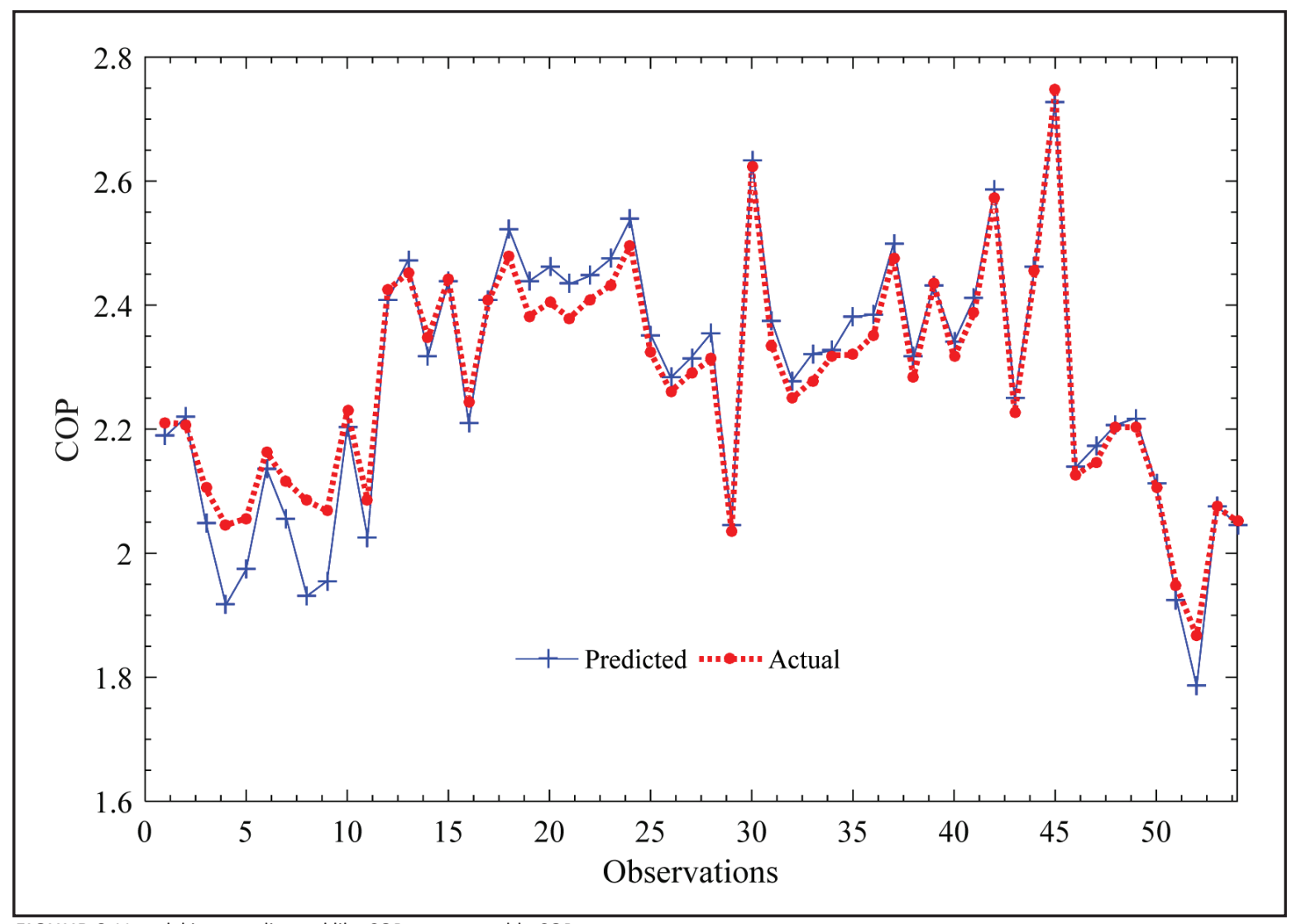

FIGUUR 6: Vergelyking van die werklike COP en voorspelde COP. 


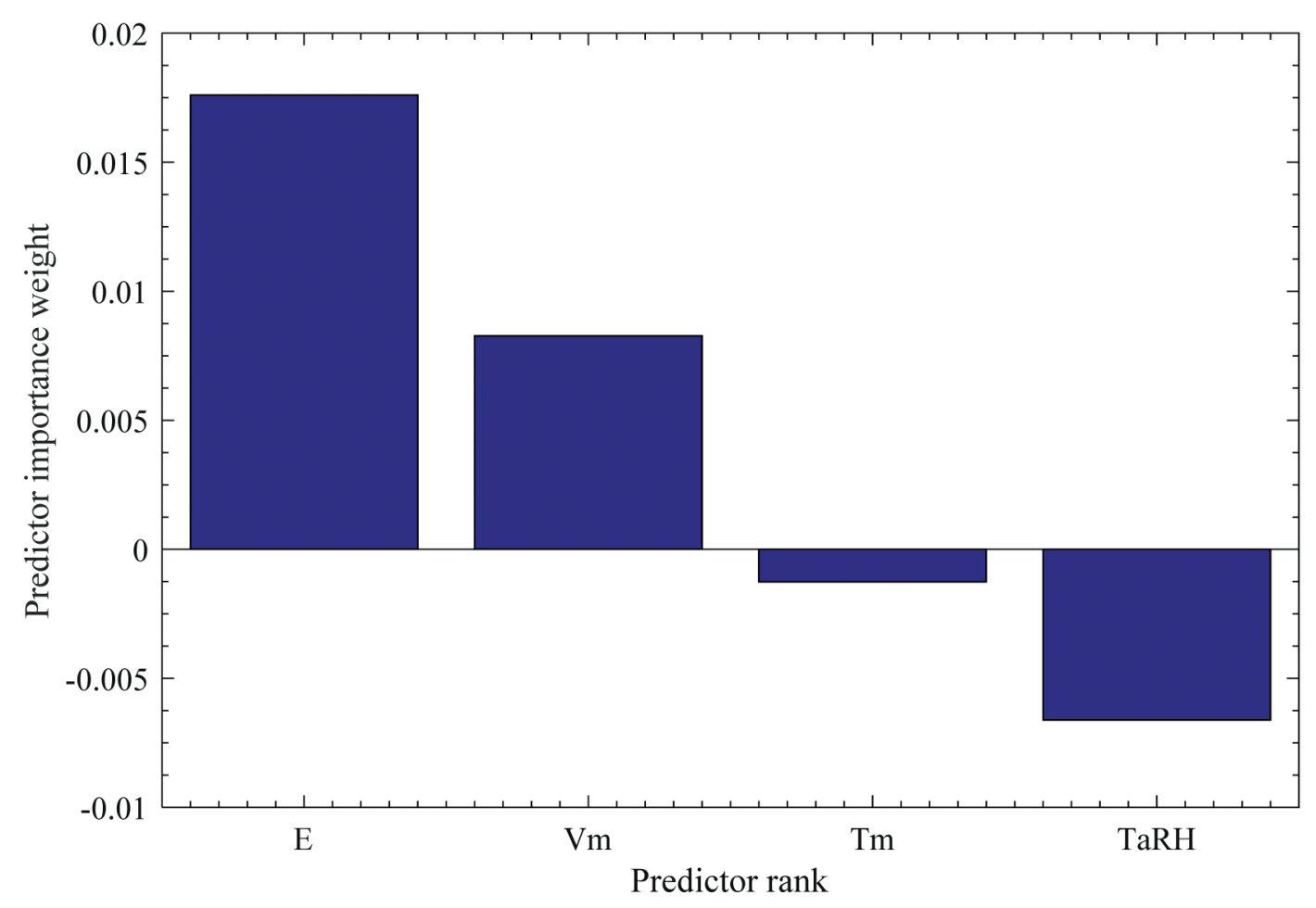

FIGUUR 7: Voorspeller posisie volgens belangrikheid

$27,52 \%\left(29,23{ }^{\circ} \mathrm{C}\right.$ tot $\left.40,33^{\circ} \mathrm{C}\right)$ sou ook die COP van die DXBMC met 0,78 verhoog. Omgewingstemperatuur en relatiewe humiditeit het 'n onbeduidende uitwerking op die COP van die stelsel gehad. Die uitwerking van die omgewing op die DXBMC se COP word toegeskryf aan die ligging daarvan op die plaas. In hierdie geval is die DXBMC geplaas sodat daar minimale interaksie met die eksterne toestande is.

\section{Modelvalidering}

Modelvalidering is uitgevoer met behulp van $30 \%$ van die data verkry uit dieselfde DAS en die soortgelyke tegnieke wat gebruik is vir die analise. Die model is gebruik vir voorspelling met die toepaslike voorspellers wat in die voorafgaande afdeling aangebied word. Die voorspellings van die model wat ontwikkel is, is daarna vergelyk met die berekende COP van die DXBMC. Die RPE is gebruik om die geskiktheid van die ontwikkelde model te evalueer, soos voorgestel deur Fuentes-Pila et al. (1996). In die lig hiervan het die model 'n RPE en RMSE van onderskeidelik $2.735 \%$ en 0.082. Dit dui daarop dat die MLR-model 'n aanvaarbare voorspellingspresisie het, aangesien die RPEwaardes wissel van $10 \%$ tot $20 \%$ (Fuentes-Pila et al., 1996). Figuur 6 illustreer die vergelyking van die werklike COP en dié wat deur die MLR voorspel word.

Soos getoon in Figuur 6, boots die voorspelde COP die werklike COP na met ' $n R^{2}$-waarde van 0,956 . Die hoë $R^{2}$ -waarde dui daarop dat die ontwikkelde model op soortgelyke direkte-uitbreiding DXBMC -stelsels gebruik kan word om die COP te voorspel.

\section{Rangskikking van voorspellers vol- gens gewigtigheid}

Die ReliefF -algoritme in die Matlab Statistical toolbox is gebruik om voorspellers te rangskik (Palm, 2010; Mhundwa et al., 2017). Die algoritme onderskei deur die berekening van die rangorde en gewigtigheid van die voorspellers, die grootte en rigting tussen primêre en sekondêre bydraers tot die gewenste uitset is ' $n$ kritieke parameters wat gebruik word. Die primêre bydraers sal 'n positiewe waarde hê, terwyl die sekondêre 'n negatiewe waarde sal hê en dit wissel van -1 tot 1 met groot positiewe gewigte wat aan essensiële eienskappe toegeken word, soos aangedui in figuur 7 .

\section{Afsluiting}

'n DXBMC op 'n plaas is gedurende April 2016-Maart 2017 gemonitor en die COP daarvan is geëvalueer met behulp van MLR-modelleringstegnieke. Op grond van ons analise is die belangrike bevindings uit hierdie studie soos volg:

i. Die COP van 'n DXBMC op 'n plaas kan met 'n hoë akkuraatheid voorspel word met behulp van 'n MLR-model met energie, die volume melk, die temperatuur van melk, relatiewe humiditeit en omgewingstemperatuur.

ii. Energieverbruik het die grootste invloed op die COP van die DXBMC, gevolg deur die volume melk, die temperatuur van melk en relatiewe humiditeit en omgewingstemperatuur, in daardie volgorde. 
iii. Energieverbruik en die volume melk dra by tot die COP, terwyl melktemperatuur en die produk van omgewingstemperatuur en relatiewe humiditeit sekondêr was as gevolg van die ligging van die DXBMC.

\section{Erkennings}

Ons is dankbaar vir die finansiële steun van die Universiteit van Fort Hare.

\section{Verwysings}

Artuso, P., Marinetti, S., Minetto, S., Del Col, D., Rossetti, A. 2020. Modelling the performance of a new cooling unit for refrigerated transport using carbon dioxide as the refrigerant. International Journal of Refrigeration, 115, pp.158171. https://doi.org/10.1016/j.ijrefrig.2020.02.032.

Bibby, J., Toutenburg, H. 1977. Prediction and improved estimation in linear models. Wiley, New York, NY.

Department Agriculture Forestry and Fisheries (DAFF), 2012. A profile of the South African dairy market value chain. Accessed from www.nda.agric.za/docs/ AMCP/Dairy2012.pdf on 17 June 2015.

Food and Agricultural Organisation Statistics (FAOSTAT). 2012.

Fuentes-Pila, J., DeLorenzo, M.A., Beede D.K., Staples C.R., Holter, J.B. 1996. Evaluation of equations based on animal factors to predict intake of lactating Holstein cows. J. Dairy Sci. 79:1562-1571. https://doi.org/10.3168/jds.S0022 0302(96)76518-9.

Lacto Data. 2015. Statistics A Milk S.A. publication compiled by the Milk Producers' Organisation, 18 (1)

Laidi, M., Hanini, S. 2013. Optimal solar COP prediction of a solar-assisted adsorption refrigeration system working with activated carbon/methanol as working pairs using direct and inverse artificial neural network. International Journal of Refrigeration, 36(1), pp.247-257. https://doi.org/10.1016/j. ijrefrig.2012.09.016.

Lee, T.S., Lu, W.C. 2010. An evaluation of empirically-based models for predicting energy performance of vapor-compression water chillers. Applied Energy, 87(11), pp.3486-3493. https://doi.org/10.1016/j.apenergy.2010.05.005.

Mhundwa, R., Simon, M. 2020. Electrical energy prediction using a surface fitting model for an on-farm direct expansion bulk milk cooler (DXBMC) in South Africa, Journal of Engineering, Design and Technology, (19) 3, pp. 778-794. https://doi.org/10.1108/JEDT-05-2020-0198.

Mhundwa, R., Simon M., Tangwe, S. 2017. Comparative analysis of the coefficient of performance of an on-farm direct expansion bulk milk cooler. International Conference on the Industrial and Commercial Use of Energy (ICUE). IEEE, 2017. https://doi.org/10.23919/ICUE.2017.8067998.
Mhundwa, R., Simon M., Tangwe, S. 2016. Low-cost empirical modelling to determine cooling savings in a dairy plant using a pre-cooler. International Conference on the Industrial and Commercial Use of Energy (ICUE). IEEE, 2016.

Murphy, M., Upton, J., O'Mahony, M. 2013. Rapid milk cooling control with varying water and energy consumption, Bio Eng. pp. 116, 15-22. https://doi. org/10.1016/j.biosystemseng.2013.05.007.

Nikbakhti, R., Wang, X., Chan, A., 2020. Performance analysis of an integrated adsorption and absorption refrigeration system. International Journal of Refrigeration, 117, pp. 269-283. https://doi.org/10.1016/j.ijrefrig.2020.04.019.

O’Keeffe, J. 2007. Milk cooling, inservice training. Teagasc, Moorepark Research Centre http://www.teagasc.ie/advisory/farm_management/buildings/ milkingEquipment/milk_cooling/MilkCoolingPresentation.pdf

Opalic, S.M., Goodwin, M.,Jiao, L., etal. 2020. ANN modelling of CO refrigerant cooling system COP in a smart warehouse. Journal of Cleaner Production, 260, p.120887. https://doi.org/10.1016/j.jclepro.2020.120887.

Peebles, R., Reinemann, D., Straub, R. 1993. Analysis of milking center energy use, Presented at the 1993 Winter Meeting of the ASAE, Chicago, Illinois, ASAE.

Peterson, R. 2008. Energy management for dairy farms. Presentation at the Farm Energy Audit Training for Field Advisors Workshop.

Rook, A.J.,Dhanoa, M.S.,Gill, M.1990. Prediction ofthevoluntaryintake ofgrasssilage bybeefcattle.Precision ofalternativepredictionmodels. Anim. Prod.50:455-466. https://doi.org/10.1017/S0003356100004931.

Sanford, S. 2003b. Well water precoolers. University of Wisconsin - Cooperative Extension Publication (A3784-3). Madison, Wisconsin: University of Wisconsin.

Sapali, S.N., Pise, S.M., Pise, A.T., Ghewade, D.V. 2014. Investigations of waste heat recovery from bulk milk cooler. Case Studies in Thermal Engineering (4), pp. 136-143. https://doi.org/10.1016/j.csite.2014.09.003.

Stinson, G.E., Studman, C.J., Warburton, D.J. (1987) A dairy refrigeration heat recovery unit and its effects on refrigeration operation. Journal of Agricultural Engineering Research $(36,4)$, pp. 275-285. https://doi.org/10.1016/0021 8634(87)90110-7.

Tian, C., Xing, Z., Pan, X., Tian, Y. 2019. A method for COP prediction of an on-site screw chiller applied in cinema. International Journal of Refrigeration, 98, pp.459-467. https://doi.org/10.1016/j.ijrefrig.2018.10.020.

Upton, J., Humphreys, J., Koerkamp, P.G., et al. 2013. Energy demand on dairy farms in Ireland. Journal of Dairy Science, 96(10), pp.6489-6498. https://doi. org/10.3168/jds.2013-6874.

Upton, J., Murphy, M., Shalloo, L., Koerkamp, P.G., De Boer, I.J.M. 2014. A mechanistic model for electricity consumption on dairy farms: Definition, validation, and demonstration. Journal of Dairy Science, 97(8), pp.4973-4984. https://doi.org/10.3168/jds.2014-8015.

Vellinga, T.V., De Haan, M.H.A., Schils, R.L.M., Evers, A., Van den Pol-van Dasselaar A. 2011. Implementation of GHG mitigation on intensive dairy farms: Farmers' preferences and variation in cost effectiveness. Livestock Science, 137(1-3) pp.185-195. https://doi.org/10.1016/j.livsci.2010.11.005. 